\title{
XXVIth Canadian Congress of Neurological Sciences
}

\section{XXVIe Congrès Canadien des Sciences Neurologiques}

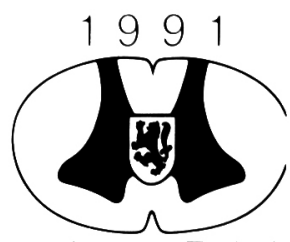

1991 Halifax, June $18-22$

\begin{tabular}{|c|}
\hline $\begin{array}{l}\text { PRELIMINARY PROGRAM } \\
\text { Tuesday, June } 18\end{array}$ \\
\hline $\begin{array}{l}\text { Satellite Meeting } \\
\text { Child Neurology Day } \\
\text { - MS Symposium }\end{array}$ \\
\hline Wednesday, June 19 \\
\hline $\begin{array}{l}\text { Congress Courses } \\
(1 / 2 \text { DAY EACH) } \\
\text { Medical/Surgical Aspects of Peripheral Nerve Disease } \\
\text { Movement Disorders } \\
\text { Neuro-ophthalmology } \\
\text { Neuro-oncology } \\
\text { Headache } \\
\text { EEG/Epilepsy - Current Practice } \\
\text { Welcoming Cocktail }\end{array}$ \\
\hline Thursday, June 20 \\
\hline $\begin{array}{l}\text { Plenary I (morning) } \\
\text { Platform Sessions (afternoon) } \\
\text { Poster Session (all day) } \\
\text { Exhibits (all day) } \\
\text { "A Maritinze Experience" }\end{array}$ \\
\hline Friday, June 21 \\
\hline $\begin{array}{l}\text { Plenary } 2 \text { (morning) } \\
\text { Platform Sessions (afternoon) } \\
\text { Poster Session (all day) } \\
\text { Exhibits (all day) }\end{array}$ \\
\hline $\begin{array}{l}\text { Saturday, June } 22 \\
\text { - Symposium (morning) } \\
\text { "The Neurobiology of Excitatory Amino Acids" }\end{array}$ \\
\hline
\end{tabular}

\section{PROGRAMME PRÉLIMINAIRE}

Mardĭ 18 juì

Rencontres par satellite

- Joumée consacrée à la neurologie pédiatrique

- Symposium sur la sctérose en plaques

Mercredi 19 juin

Cours du congrèss

\section{(DEMIE-JOURNÉE)}

- Aspects médicaux et chirurgicaux de la netropathie périphérique

- Troubles du nouvement

- Neuro-ophthalmologie

- Neuro-oncologie

- Mal de tête

- EEG/Épilepsie - Pratique courante

- Cocktail d ouverture

Jeudi 20 juin

- Plénière 1 (matinée)

- Présentations orales (matinée et après-midi)

- Affiches (joumée entiere)

- Exposition (journée entière)

. "Une expérience maritime"

Vendredi 21 juin

- Plénière 2 (matinée)

- Présentations orales (après-midi)

- Affiches (joumée entière)

- Exposition (joumée entiére)

Samedi 22 juin

- Colloque (matin)

"La neurobiologie des acides aminés excitateurs" 